\title{
Aspectos clínicos e epidemiológicos da broncopneumonia dos bezerros em Botucatu, SP
}

\section{Clinical and epidemiological aspects of calf pneumonia in Botucatu, SP}

\author{
Roberto Calderon Gonçalves, ${ }^{\star}$ Júlio Augusto Naylor Lisbôa, ${ }^{\star \star}$ Maria Verônica de Sousa, ${ }^{\star \star \star}$ Clóvis Teixeira de Almeida, ${ }^{*}$ \\ Márcio Rubens Graf Kuchembuck, ${ }^{\star \star \star *}$ Simone Biagio Chiacchio*
}

\begin{abstract}
Resumo
Com o objetivo de avaliar alguns aspectos epidemiológicos e clínicos relacionados à broncopneumonia dos bezerros, realizou-se um levantamento dos registros clínicos individuais de 133 bovinos acometidos, do nascimento aos 12 meses de idade, em um total de 1084 assistidos pelo serviço ambulatorial de Clínica de Grandes Animais do Hospital Veterinário da Faculdade de Medicina Veterinária e Zootecnia da UNESP, Botucatu, durante o período de 1980 a 1991 . Determinaram-se as distribuições de freqüência da broncopneumonia quanto aos meses do ano, idade, sexo, etiologia provável e associação com outras afecções, e estudaram-se a presença de dispnéia, tosse, corrimento nasal e ruídos respiratórios adventícios, além de coloração das mucosas, grau de desidratação, temperatura corporal e freqüências cardíaca e respiratória. Os resultados apontaram a broncopneumonia como um problema relativamente comum $(12,27 \%)$, com predomínio das infecções viral e/ou bacteriana $(89,47 \%)$, especialmente nos cinco primeiros meses de vida, seguidas pela dictiocaulose $(10,53 \%)$, a partir do sexto mês de idade, como a etiologia provável, sem comportamento sazonal ou predileção por sexo, e em freqüente concomitância com outras afeç̧ões $(60,9 \%)$, como a diarréia e a anaplasmose. Os animais estudados demonstraram variadamente dispnéia, tosse, corrimento nasal, hipertermia e taquicardia, e, consistentemente taquipnéia e ruídos respiratórios exacerbados com estertores à auscultação pulmonar.
\end{abstract}

Palavras-chave: bezerro; pneumonia; epidemiologia; clínica.

\begin{abstract}
A survey of data related to 133 pneumonic calves, from birth to 12 month-old, referred to the Large Animal Medicine Ambulatory of the Veterinary Teaching Hospital, UNESP, Botucatu, between 1980 and 1991, was made in order to evaluate some epidemiological and clinical aspects, including distribuition by month, age, sex, probable etiology and association with other diseases; presence of dyspnea, cough, nasal discharge and adventitious lung sounds; dehydration status, temperature and cardiac and repiratory rates. The results showed that calf pneumonia is a relatively common problem $(12,27 \%)$, usually caused by viral and/or bacterial $(89,47 \%)$ infections and dictiocaulosis $(10,53 \%)$, in animals up to and above the age of 6 months, respectively, with no seazonal pattern or sex predilection, and frequently concomitant with other diseases $(60,9 \%)$, like diarrhea and anaplasmosis. The affected calves showed variably dyspnea, cough, nasal discharge, hyperthermia and tachycardia, and consistently tachypnea, and increased intensity breath sounds and adventitous sounds detected on pulmonary auscultation.
\end{abstract}

Keywords: calf; pneumonia; epidemiology; medicine.

\section{Introdução}

Dentre as afecções de bezerros, os processos inflamatórios pulmonares apresentam grande importância (Ribeiro et al., 1983; Radostits et al., 1994), determinando significativos prejuízos do ponto de vista econômico e de saúde animal.

Estão implicados na etiologia diferentes agentes virais e bacterianos, muitas vezes associados entre si, além do
Dictiocaulus sp. (Radostits et al., 1994). Deve-se ressaltar a participação fundamental, com interação complexa, de vários fatores predisponentes, relacionados a falhas ou modificações súbitas nos manejos sanitário, nutricional e de instalações (Bryson, 1985; Smith, 1990; Hjerpe, 1993).

As manifestações clínicas refletem o comprometimento da capacidade respiratória e são variáveis de acordo com a extensão do parênquima pulmonar afetado (Dirksen et al., 1993;

\footnotetext{
* Professor Assistente do Depto de Clínica Veterinária - FMVZ - UNESP - Botucatu, SP.

** Professor Assistente do Depto de Clínicas Veterinárias - UEL - Londrina, PR. Autor para correspondência Departamento de Clínicas Veterinárias Centro de Ciências Agrárias - UEL - Campus Universitário, CEP 86051-970, Londrina PR - Fone: 371-4319.

*** Professor Assistente do Depto de Medicina Veterinária - UFV - Viçosa, MG.

**** Professor Titular do Depto de Clínica Veterinária - FMVZ - UNESP - Botucatu, SP.
} 
Radostits et al., 1994), porém, independem, em geral, dos agentes etiológicos envolvidos.

Utilizando-se de informações da casuística hospitalar em 12 anos consecutivos, o presente trabalho traz como objetivo 0 estudo de certos aspectos epidemiológicos e clínicos relacionados ao quadro de broncopneumonia nos bezerros.

\section{Material e método}

\section{Levantamento de dados}

Procedeu-se, junto ao serviço de arquivo do Hospital Veterinário da Faculdade de Medicina Veterinária e Zootecnia da UNESP, Campus de Botucatu, ao levantamento dos registros clínicos individuais referentes aos bovinos, do nascimento ' aos 12 meses de idade, assistidos no ambulatório de Clínica Médica de Grandes Animais, durante o período compreendido entre os anos de 1980 e 1991, considerando-se o total de bezerros encaminhados $(n=1084)$ e, especificamente, daqueles acometidos por broncopneumonia $(n=133)$. Os animais em questão eram provenientes de propriedades rurais localizadas no município de Botucatu e vizinhos, Estado de São Paulo.

Os dados explorados no trabalho basearam-se nas informações registradas em protocolos clínicos específicos e individuais, sob orientação da mesma equipe, durante todo o período considerado.

\section{Dados epidemiológicos}

Estudaram-se os seguintes aspectos epidemiológicos relacionados à ocorrência de broncopneumonia: distribuição quanto aos meses do ano, à idade, ao sexo, à etiologia provável, e quanto à associação com outras afecções (diarréia, anaplasmose e babesiose).

As prováveis causas da broncopneumonia foram divididas em duas categorias, a saber: viral e/ou bacteriana e dictiocaulose, definidas fundamentalmente por meio de informações clínicas (histórico, exame físico e resposta ao tratamento instituído), com auxílio radiológico em alguns casos, e laboratoriais (pesquisa de larvas de Dictiocaulus sp. nas fezes, e achados de necrópsia e histopatologia, quando pertinentes). O processamento laboratorial de amostras de secreção nasal, aspirado de lavagem traqueal ou material de necrópsia visando à definição do diagnóstico de agentes virais e bacterianos foi realizado em um número reduzido de casos, sendo este 0 motivo para a referência genérica e conjunta de ambas as infecções e para a utilização do termo "provável etiologia".

A identificação dos bezerros portadores de babesiose e/ou anaplasmose concomitantemente à broncopneumonia, foi possível mediante o exame ao microscópio óptico de esfregaços sangüíneos corados seguindo as recomendações da literatura (Jain, 1986); e a manifestação de diarréia evidenciada durante a exploração clínica.

\section{Dados clínicos}

Os bezerros acometidos ( $n=133$ ) foram submetidos ao exame clínico rotineiro, empregando-se os métodos semiológicos classicamente preconizados (Dirksen et al., 1993), com des- taque para o estudo das presenças de: dispnéia, tosse, e corrimento nasal uni ou bilateral, classificado quanto ao tipo em seroso, seromucoso, mucoso, mucopurulento e purulento; além dos achados de auscultação torácica, segundo as evidências de ruídos respiratórios exacerbados, áreas de silêncio auscultatório e presença de ruídos adventícios (crepitação e/ou sibilo). Avaliaram-se, adicionalmente, a característica de coloração das mucosas e o grau de desidratação, respectivamente classificados como: róseas, pálidas, perláceas e vermelhas (congestas), e ausente, leve (5 a $8 \%$ ), moderado (8 a 10\%) e intenso (acima de 10\% PV).

Para o estudo das funções vitais incluíram-se os bezerros acometidos unicamente por broncopneumonia $(n=50)$, os quais foram divididos em dois grupos segundo a faixa etária; do nascimento aos dois meses $(n=22)$ e acima de dois meses $(n=28)$, com a finalidade de comparação com os valores de referência apontados por Baccari Jr. (1971 e 1973), considerando-se como fisiológicos a temperatura de 38,0 a $39,5^{\circ} \mathrm{C}$; a freqüência cardíaca de 100 a 120 (até dois meses) e de 60 a 90 (acima de dois meses) batimentos por minuto; e a freqüência respiratória de 40 a 50 (até dois meses) e de 25 a 40 (acima de dois meses) movimentos por minuto.

\section{Análise estatística}

Efetuou-se um estudo estatístico descritivo, determinandose medidas de tendência central e de dispersão para as variáveis quantitativas, e as distribuições de freqüências para as variáveis qualitativas.

\section{Resultados e discussão}

A análise dos dados levantados revelou que, dentre os bezerros assistidos no intervalo de tempo estudado, $12,27 \%$ apresentavam broncopneumonia, tratando-se, portanto, de uma entidade clínica relativamente freqüente nesta categoria animal. Não foi verificada variação significativa na freqüência da enfermidade entre os diferentes 12 anos investigados.

$\mathrm{Na}$ Figura 1 pode-se apreciar a distribuição dos casos segundo os meses do ano, demonstrando a inexistência de um padrão de comportamento sazonal, pois, com exceção da evidente concentração no mês de setembro, não houve qualquer diferença expressiva entre a população geral de bezerros atendidos e a de portadores de broncopneumonia. Este achado contradiz, em parte, o conceito de que o período de inverno, naturalmente caracterizado por baixos índices de temperatura ambiental e de umidade relativa do ar, constitui-se na época mais propícia para o surgimento de problemas respiratórios (Bryson, 1985; Smith, 1990). Devem-se considerar, entretanto, os óbvios contrastes climáticos entre os países tropicais e aqueles de clima temperado, sendo que, nos últimos, ao contrário do que ocorre no Brasil, o confinamento dos animais durante os meses frios é uma prática de manejo quase que obrigatória, o que pode representar importante fator predisponente para o problema em estudo (Bryson, 1985; Smith, 1990; Hjerpe, 1993).

Quanto à idade, observou-se uma incidência maior nos cinco meses iniciais de vida, particularmente o primeiro (Figura 2), o que concorda com a citação de Smith (1990). No que diz respeito ao sexo, não se verificou diferença significativa entre machos $(45,11 \%)$ e fêmeas $(54,89 \%)$. 


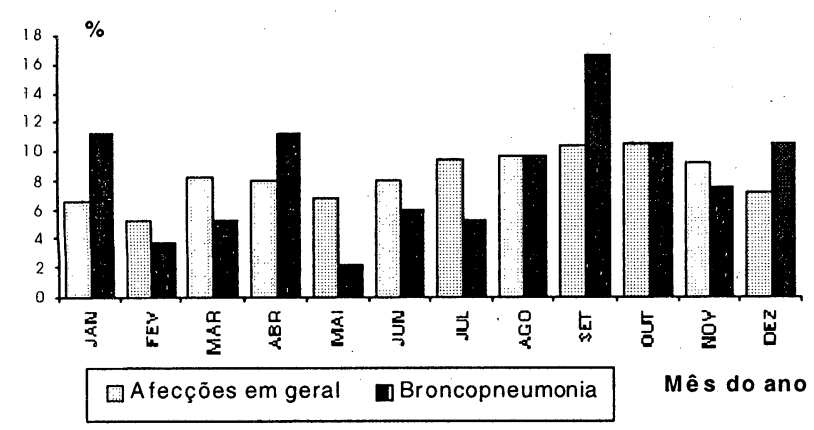

Figura 1: Distribuição de freqüências, em relação aos meses do ano, dos bezerros portadores de afecções em geral $(n=1084)$ e, especificamente, de broncopneumonia $(n=133$ ), encaminhados ao Hospital Veterinário-FMVZUNESP-Botucatu, no período entre 1980 e 1991.

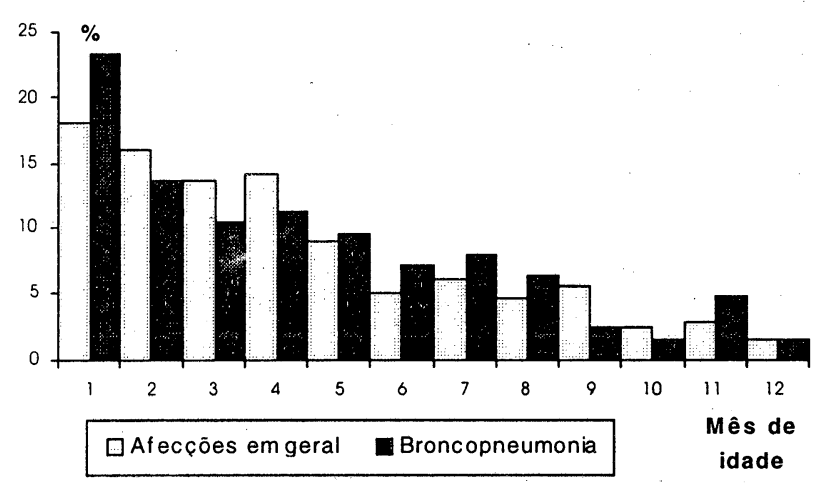

Figura 2: Distribuição de frequeências, quanto à faixa etária, dos bezerros portadores de afecçōes em geral $(n=1084)$ e, especificamente, de broncopneumonia $(n=133$ ), encaminhados ao Hospital Veterinário-FMVZ-UNESP-Botucatu no período entre 1980 e 1991 .

Dentre as etiologias prováveis, houve um predomínio absoluto das infecções virais e/ou bacterianas sobre as parasitárias (Figura 3), sendo estas observadas em bezerros somente a partir do sexto mês de idade (Figura 4), na sua grande maioria de raças de corte, mantidos em manejo extensivo e coincidindo com o desmame ou início do período de recria. Ao contrário dos quadros de dictiocaulose, os demais casos concentraram-se em bezerros mais jovens, em especial no período neonatal, considerando-o até os 30 dias de idade. Nestes, as informações de anamnese puderam sugerir o envolvimento de vários fatores associados ou não entre si, tais como falha na transferência de imunidade passiva com susceptibilidade a infecções neonatais, subnutrição e manejo confinado com superlotação em, pelo menos, parte do dia, em ambientes pouco ventilados e cama erroneamente manejada.

A consistente associação da broncopneumonia com outras afecções em $60,9 \%$ dos casos, destacando-se a diarréia e a anaplasmose (Figura. 5), reforça a hipótese de menor resistência às infecções, e está de acordo com as colocações de Ribeiro et al. (1983), considerando-as çomo as três causas principais de mortalidade em bezerros.

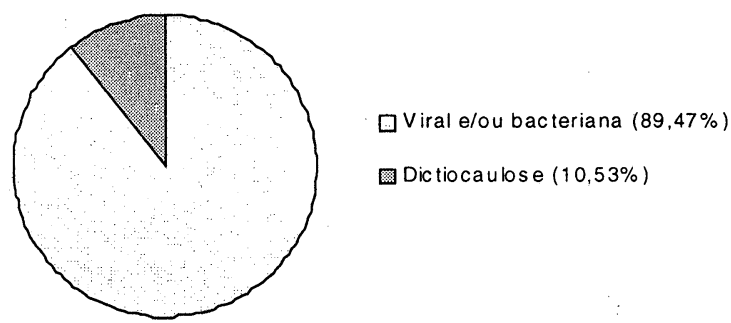

Figura 3: Distribuição de freqüências, quanto à etiologia, dos casos de broncopneumonia nos bezerros $(n=133)$ encaminhados ao Hospital Veterinário-FMVZ-UNESP-Botucatu, no período entre 1980 e 1991.

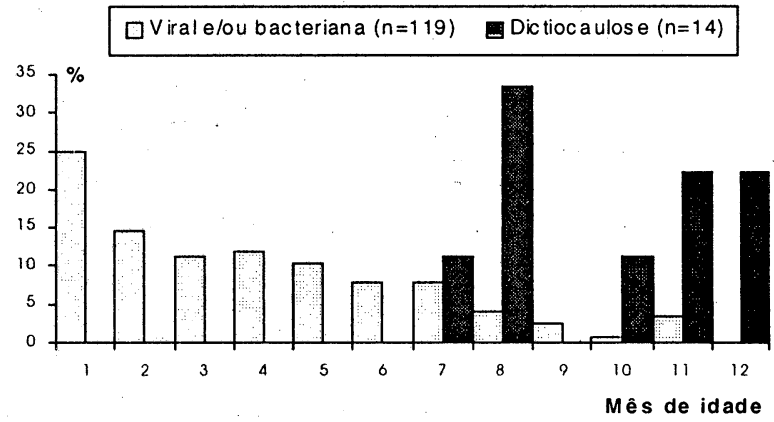

Figura 4: Distribuição de freqüências, quanto à faixa etária, dos bezerros portadores de broncopneumonia $(n=133)$ segundo a etiologia, encaminhados ao Hospital Veterinário-FMVZ-UNESP-Botucatu, no período entre 1980 e 1991.

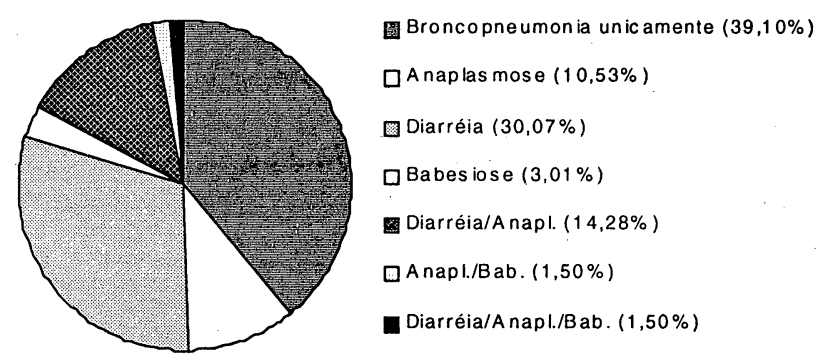

Figura 5: Distribuição de freqüências dos casos de broncopneumonia segundo a presença ou não de associação com outras doenças, em bezerros $(n=133)$ encaminhados ao Hospital Veterinário-FMVZ-UNESP. Botucatu, no período entre 1980 e 1991.

(Anapl.: Anaplasmose; Bab.: Babesiose)

Quanto aos achados clínicos, a Figura 6 ilustra a marcante presença, porém não obrigatória, de dispnéia e/ou tosse, muito embora, se analisadas em separado, tenham ocorrido em torno de somente a metade dos casos, assim como o corrimento nasal bilateral, com predomínio dos tipos mucoso e purulento. A auscultação torácica mostrou-se, por sua vez, de elevado valor diagnóstico, particularmente no que diz respeito à detecção, quase absoluta, de exacerbação dos ruídos respiratórios, além da freqüente presença de sibilo e/ou crepitação. A grande variabilidade na ocorrência das diferentes manifestações apontadas anteriormente deve ser interpretada como provável reflexo da diversidade no tempo de evolução, gravidade e extensão do comprometimento do parênquima pulmonar entre os quadros acompanhados, no momento da realização do exame clínico (Dirksen et al., 1993; Radostits et al., 1994).

Uma elevada porcentagem dos bezerros estudados apresentava graus leve $(30,3 \%)$, moderado $(18,8 \%)$ e intenso $(13,1 \%)$ 
de desidratação, possivelmente em virtude da freqüente presença concomitante de diarréia. Fato semelhante observou-se para a marcante palidez de mucosas $(44,5 \%)$ dado à associação com as infecções por hematozoários, sendo as restantes distribuídas em róseas $(35,2 \%)$ e vermelhas $(20,3 \%)$.

Por fim, o estudo das funções vitais, considerando-se os bezerros acometidos exclusivamente por broncopneumonia, apontou a taquipnéia como a alteração mais consistente (Tabela 1), revelando hipertemia e taquicardia nos animais do nascimento aos dois meses e acima desta idade, respectivamente. Tais achados são compativeis com o relativo prejuízo da capacidade ventilatória decorrente do processo inflamatório no parênquima pulmonar, bem como com os reflexos sistêmicos do mesmo, caracterizando possivelmente a síndrome febre, aliada ou não à possibilidade de graus variados de endotoxemia (Smith, 1990; Dirksen et al., 1993; Radostits et al., 1994).
Tabela 1: Apresentação de média (x), desvio-padrão (s) e mediana (Md) das funções vitais: temperatura e freqüências cardíaca e respiratória em bezerros portadores de broncopneumonia, separados por faixa etária, e encaminhados ao Hospital Veterinário-FMVZ-UNESP. Botucatu, no período entre 1980 e 1991

\begin{tabular}{|c|c|c|c|c|c|c|}
\hline $\begin{array}{l}\text { Funcáo } \\
\text { Vital }\end{array}$ & $\begin{array}{l}\text { Fana } \\
\text { etaria }\end{array}$ & $n$ & $x$ & 5 & Md & 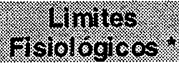 \\
\hline $\begin{array}{c}\text { Temperatura } \\
\left({ }^{\circ} \mathrm{C}\right)\end{array}$ & $\begin{array}{l}\text { até } 2 \text { meses } \\
2 \text { a } 12 \text { meses }\end{array}$ & $\begin{array}{l}22 \\
28\end{array}$ & $\begin{array}{l}39,37 \\
39,08\end{array}$ & $\begin{array}{l}1,34 \\
1,43\end{array}$ & $\begin{array}{l}39,85 \\
39,40\end{array}$ & $\begin{array}{l}38,0 \text { a } 39,5 \\
38,0 \text { a } 39,5\end{array}$ \\
\hline $\begin{array}{c}\text { Freqüência } \\
\text { cardiaca } \\
\text { (bat/min) }\end{array}$ & $\begin{array}{l}\text { até } 2 \text { meses } \\
2 \text { a } 12 \text { meses }\end{array}$ & $\begin{array}{l}22 \\
28\end{array}$ & $\begin{array}{c}112,54 \\
96,93\end{array}$ & $\begin{array}{l}25,48 \\
24,93\end{array}$ & $\begin{array}{l}106,00 \\
100,00\end{array}$ & $\begin{array}{c}100 \text { a } 120 \\
60 \text { a } 90\end{array}$ \\
\hline $\begin{array}{c}\text { Freqüência } \\
\text { respiratória } \\
\text { (bat/min) }\end{array}$ & $\begin{array}{l}\text { até } 2 \text { meses } \\
2 \text { a } 12 \text { meses }\end{array}$ & $\begin{array}{l}22 \\
28\end{array}$ & $\begin{array}{l}58,54 \\
53,68\end{array}$ & $\begin{array}{l}24,74 \\
33,37\end{array}$ & $\begin{array}{l}54,00 \\
42,00\end{array}$ & $\begin{array}{l}40 \text { a } 50 \\
25 \text { a } 40\end{array}$ \\
\hline
\end{tabular}

Boccari Jr. (1971; 1973)

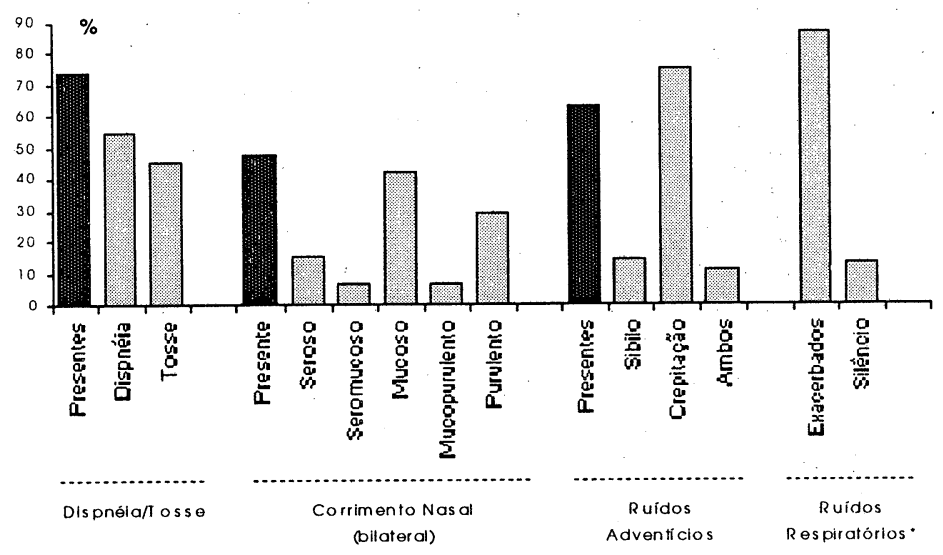

Figura 6: Apresentação e características de dispnéia, tosse, corrimento nasal e achados de auscultação pulmonar nos bezerros portadores de broncopneumonia $(n=133)$ encaminhados ao Hospital Veterinário-FMVZ-UNESP-Botucatu, no período entre 1980 e 1991.

( ${ }^{*}$ som traqueo-brônquico e bronco-bronquiolar)

\section{Conclusões}

Nas condições em que se desenvolveu o estudo, pôde-se concluir que os processos de broncopneumonia são relativamente freqüentes nos bezerros, em especial nos primeiros meses de vida, sendo principalmente provocados por infecções virais e/ou bacterianas, não apresentando comportamento sazonal ou predileção por sexo, e podendo ocorrer em concomitância à diarréia e/ou anaplasmose.

A dictiocaulose, embora menos freqüente, ocorreu em bezerros acima dos seis meses de idade.

Do ponto de vista clínico, os animais exibiram, variadamente, dispnéia, tosse, corrimento nasal, hipertermia e taquicardia; e consistentemente, taquipnéia, além de exacerbação dos ruídos respiratórios e estertores à auscultação pulmonar.

\section{Referências bibliográficas}

BACCARI JR., F. Estudo da freqüência respiratória, cardíaca e da temperatura retal em bovinos leiteiros da espécie Bos taurus. I. Efeito da idade. II. Grupos etários. Valores normais em condições naturais de clima tropical. III. Comparação entre raças, sexos e períodos do dia. Belo Horizonte, 1971. 43 p. Tese (Mestrado em Medicina Veterinária) - Escola de Veterinária, Universidade Federal de Minas Gerais.

. Freqüência respiratória, freqüência cardíaca e temperatura retal em bovinos Gir, Nelore e Guzerá em crescimento; influência da idade, raça, sexo e período do dia. Botucatu, 1973. 55 p. Tese (Doutorado) - Faculdade de Medicina Veterinária e Zootecnia, Universidade Estadual Paulista.

BRYSON, D.G. Calf pneumonia. Vet. Clin. North Am.: Food Anim. Pract., Philadelphia, v.1, n. 2., p. 237-257, 1985.
DIRKSEN, G., GRÜNDER, H.D., STÖBER, M.Rosemberger-Exame Clínico dos Bovinos. 3. ed. Rio de Janeiro: Ed. Guanabara Koogan, 1993.419p.

HJERPE, C.A. The bovine respiratory disease complex. In: HOWARD, J.L. Current Veterinary Therapy - Food Animal Practice. 3. ed. Philadelphia: W.B. Saunders Company, p. 653-664, 1993.

JAIN, N.C. Schalm's Veterinary Hematology. 4. ed. Philadelphia: Lea \& Febiger, 1986. 1.220 p.

RADOSTITS, O.M., BLOOD, D.C., GAY, C.C. Veterinary Medicine. 8. ed. London: Baillière Tindall, 1994. 1.763 p.

RIBEIRO, M.F.B., SALCEDO, J.H.P., SANTOS, J.L. et al. Inquérito de opinião com criadores da Zona da Mata do Estado de Minas Gerais: I. Alguns fatores associados com mortalidade de bezerros. Arq. Bras. Med. Vet. Zoot., Belo Horizonte, v. 35, n. 4, p. 547-556, 1983.

SMITH, J.A. Enzootic calf pneumonia. In: SMITH, B.P. Large Animal Intemal Medicine. St. Louis: C.V. Mosby Company, p. 579-581, 1990. 